Provided for non-commercial research and education use. Not for reproduction, distribution or commercial use.

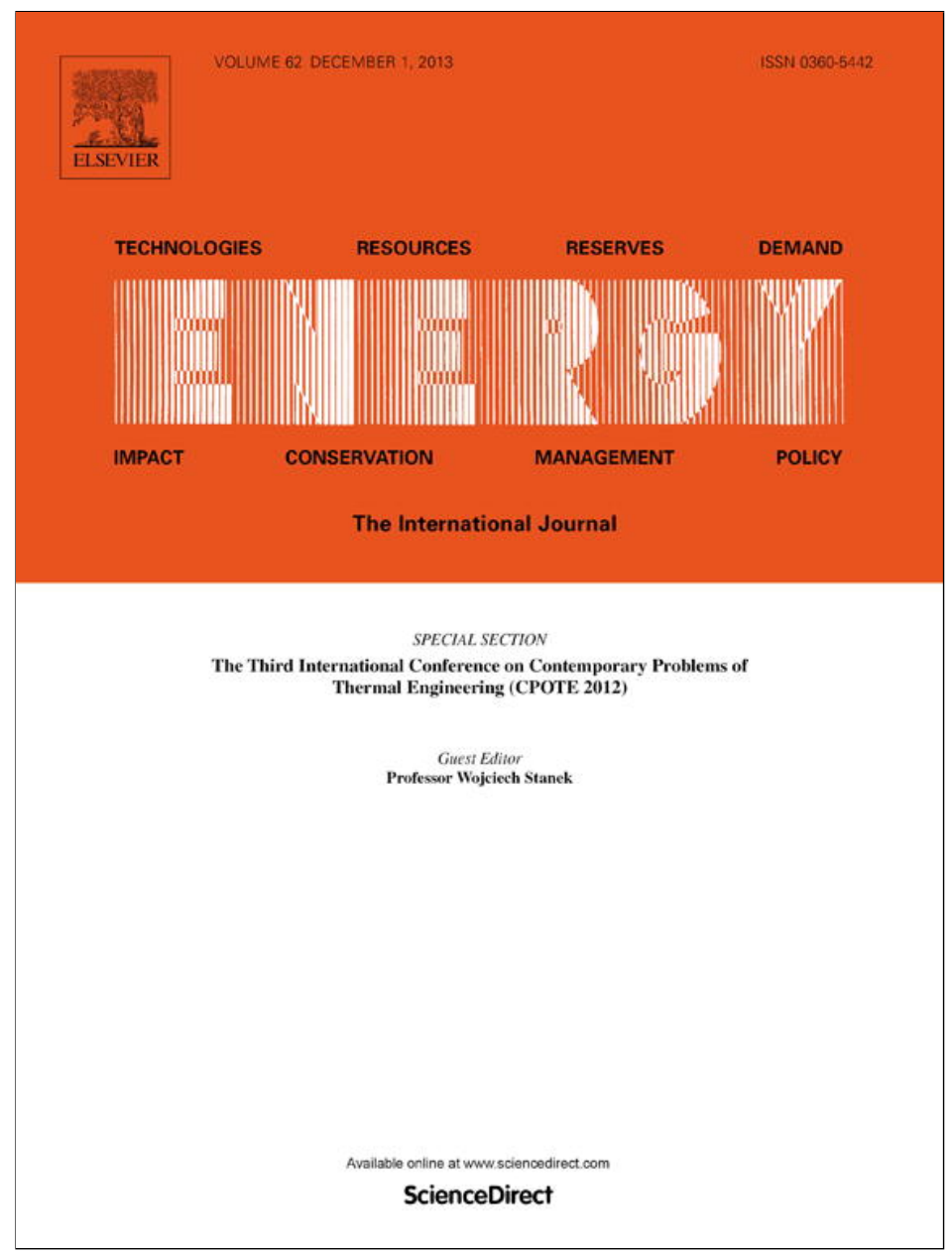

This article appeared in a journal published by Elsevier. The attached copy is furnished to the author for internal non-commercial research and education use, including for instruction at the authors institution and sharing with colleagues.

Other uses, including reproduction and distribution, or selling or licensing copies, or posting to personal, institutional or third party websites are prohibited.

In most cases authors are permitted to post their version of the article (e.g. in Word or Tex form) to their personal website or institutional repository. Authors requiring further information regarding Elsevier's archiving and manuscript policies are encouraged to visit:

http://www.elsevier.com/authorsrights 


\title{
Effects of the Italian financial crisis on the photovoltaic dissemination in a southern city
}

\author{
Aldo Orioli*, Alessandra Di Gangi \\ D.E.I.M. Dipartimento di Energia, Ingegneria dell'Informazione e Modelli Matematici, Università degli Studi di Palermo, Viale delle Scienze Edificio 9, 90128 \\ Palermo, Italy
}

\section{A R T I C L E I N F O}

\section{Article history:}

Received 31 August 2012

Received in revised form

13 September 2013

Accepted 15 September 2013

Available online 10 October 2013

\section{Keywords:}

Photovoltaic

Grid-connected photovoltaic systems

Financial crisis

Economic parameters

\begin{abstract}
A B S T R A C T
The aim of this paper is to estimate how the profitability of grid-connected PV (photovoltaic) systems may vary month by month due to the changes in all parameters involved in the economic evaluation (discount rate, PV electricity selling price, inflation rate, price of PV devices etc.). The effects of these variations were investigated for a district of a city in the South Italy (Palermo). The results of the analysis provided the trend of the actual coverage of the district power demand from June 2010 to August 2012. In particular the load match index, which considers the daily energy demand covered by PV systems, ranged from almost $30 \%$ to less than $12 \%$, which is less than the value of $17 \%$ of the final energy consumption in 2020 from renewable energy sources that Italy is obliged to ensure by the European Union Directive 2009/28/EC.

Finally, a sensitivity analysis related to shading and mismatch factors was carried out. If $10 \%$ of the solar energy had been shadowed, the load match index would have reduced of $70 \%$. Similarly, if only $40 \%$ of electrical production had been used, the load match index would have lowered to an almost null value in January 2012.
\end{abstract}

(c) 2013 Elsevier Ltd. All rights reserved.

\section{Introduction}

In times of economy recession, when people may be reluctant to invest in PV (photovoltaic) systems, it is important to estimate the economic profitability of the installation especially in high density residential areas, which are usually affected by the shortage of roofs surface available for each building co-owner.

The assessment of the economic feasibility of PV systems requires an accurate analysis based on the evaluation of all costs and benefits. The crucial factors involved in the assessment are the value of the discount rate, PV devices costs, selling and purchasing power prices and FIT (feed-in tariffs). Some of these variables may rapidly change due to a financial crisis even if some costs may be regulated, guaranteed in power purchase agreements or be at arm's length of Government control and interference. The deviation of each economic parameter definitely affects the decision of a householder who would want to invest in the PV technology. In the last years Italy and other countries, like Spain and Germany, have heavily reduced the incentives to support PV installations. At the end of 2010 the Spanish government adopted a drastic

\footnotetext{
* Corresponding author. Tel.: +39 (0)9123861914 905; fax: +39 (0)91484425.

E-mail addresses: orioli@dream.unipa.it, aldo.orioli@unipa.it (A. Orioli).
}

reduction of $45 \%$ in feed-in-tariff for non-integrated installations, $25 \%$ for building integrated installations above $20 \mathrm{~kW}$ and $5 \%$ for systems up to $20 \mathrm{~kW}$ [1]. In January 2012 the Spanish government temporarily stopped incentivizing new projects starting after January 2013 [2]. Since January 2012, Germany has raised to 15\% the yearly reduction in FIT incentives, which was originally fixed to $9 \%$ [3]. The shift from the initial generous values, which is connected both to the predicted drop in the PV devices price and significant total installed solar PV capacity, does not ensure that FIT payments will be able to adequately cover the investment and management costs.

The role of incentives in the economic assessment of renewable energy sources was analysed by many authors. Celik [4] claimed the need of economic subsidies in order to propagate the alternative energy systems. Stritih [5] pointed out that the most suitable mode to stimulate power production from renewable energy sources were feed-in-tariff systems and soft loans. A uniform price of $37.36 € \mathrm{cent} / \mathrm{kWh}$ and a premium of $34.03 €$ cent $/ \mathrm{kWh}$ were set by Republic of Slovenia for the purchase of electricity from qualified producers. Zahedi [6] used an economical model to determine the unit price of solar PV electricity, which will be valid for all states of Australia, in order to accurately determine the most appropriate FIT of grid connected solar PV energy systems. Poullikkas [7] observed 
that the economic feasibility of large PV parks in Cyprus, in absence of appropriate FIT, has a critical value. Danchev et al. [8] showed that the rate of FIT de-escalation does not guarantee return rate over the time in Greece. They concluded that the feed-in tariffs should have been higher by $85-175 \%$ (depending on PVS's (Photovoltaic systems) location and size) in 2020 than the current projections. Papadopoulos et al. [9] discussed a quantitative assessment of the FIT introduced in Greece. They claimed that the Greek FIT should be adjusted with respect to the region/area of installation, in order to avoid excessive profits for the investors in areas with high insolation but also to offset the solar potential in less favourable regions (such as northern Greece) and hence create viable conditions for PVs. Campoccia et al. [10] compared the supporting measures adopted by France, Germany, Italy and Spain and observed that FITs' strategy led to pay-back periods not over 19 years for small and medium-sized building integrated PV systems in all the considered countries. FITs for big-sized not integrated PV systems were advantageous only in Germany and Italy while in France and Spain the pay-back period was never reached in 25 years. The PV policies in Germany, Spain and Greece were analysed by Lüthi [11] who observed that above a certain level of return, riskrelated factors (such as policy instability and administrative hurdles) played a more important role in influencing investment decisions than return-related factors (such as the level of a feed-in tariff). Rigter et al. [12] calculated what the level of tariffs would have to be in China. The appropriate FIT values resulted $0.44 \$ / \mathrm{kWh}$ for the sun rich region of Qinghai and $0.77 \$ / \mathrm{kWh}$ for the central municipality of Chongqing. Dusonchet et al. $[13,14]$ extended the comparison of supporting measures to 17 western and 10 eastern European Union countries. Dinçer [15] analysed the PV electricity status, potential ad policies of Spain, Germany, United States of America, Japan and China and claimed that to achieve a measurable impact on market growth and to reach a diverse cross-section of users, retail financing terms need to be flexible. Moreover, investor should be given variety of important incentives for increased use of solar energy, for example, increasing prices of solar energy purchases by the governments, to be exempt from purchase of PV panels can be increased. Sivaraman et al. [16] examined the Australian policy to increase small scale grid-connected PV deployment. They observed that, notwithstanding the potential effects of FITs, the creation of market incentives in Australia could not be expected to herald technology transitions in themselves. AlBadi et al. [17] discussed the renewable energy support policies that can be implemented in Oman and claimed that the most effective mechanism was the FIT, even if they did not propose any specific FIT rate to be adopted.

By means of the learning-curve methodology, Van der Zwaan et al. [18] stated that, mainly due to its high cost, PV electricity was unlikely to pay a major role in the global energy supply and carbon emission abatement before 2020. Celik et al. [19] analysed the energy statistics of 15 European Union countries and inferred that subsides and incentives are vital in promoting solar thermal and PV collectors. Kelleher [20] estimated the economics of renewable microgeneration of electricity from wind and solar energy sources. Hongbo et al. [21] performed the economic optimization and sensitivity analysis of PV systems in residential buildings. AlSalaymeh et al. [22] observed that the installation of PV systems in a residential flat in Jordan may not be economically rewarding due to the high cost of the PV system compared to the cost of the grid electricity; on the contrary, PV systems may be economically advantageous if applied in locations far from the electrical grid. Li [23] presented a realistic economic analysis of eight sample domestic solar PV systems in Ireland. The mismatch between generated and consumed electricity may also produce important effects in the viability of PV systems. Myers et al. [24] assumed that the investment in solar PV in Wisconsin approached a practical limit due to the available solar radiation and mismatch between demand and electrical generation.

A matter of considerable importance to correctly estimate the influence of PV technology is also represented by the kind of the examined context. Actually, when a PV system is installed on the roof of a simple one-family detached house, each technical detail (panels, inverters, orientation, pitch), and economic aspect (costs for execution, maintenance, servicing, inflation and insurance) can be defined [4,25-28], but the predicted results, though extremely accurate and realistic, will not have a general validity. Vice versa, when the study is aimed to the PV energy assessment of a wide urban context, it is extremely complex to consider all details that affect the results [29-32].

Many different techniques were used to estimate the collecting surfaces of roofs. In several studies on building-integrated solar energy applications the amount of available area was assumed as an input data [33-36]. For city areas, vectorial GIS (Geographic information system) orthomaps [31,34,35] and urban maps obtained from Google Earth ${ }^{\mathrm{TM}}$ [33], were used to create polygon objects representing the building roofs. The estimation of the region areas was performed using the machine leaner functions and classification algorithms of Feature Analyst, which is an advanced feature extraction program existing as an extension of ArcGIS [37], and the open source GRASS (Geographical Resource Analysis System) [38]. For continent and subcontinent areas CORINE Land Cover and GIS databases were also used [30,39].

The authors proposed an innovative procedure [40] that permits to extend the results of predictions to the totality of housing types of a city or region by considering each specific parameter of the problem (panels, inverters, orientation, pitch, obstructions, economic indexes). In the present paper the same procedure is used to carry out an analysis by a time transitory point of view in order to answer the question: how a householder would reach the decision of installing a PV system on the roof of his house if the country where he lives was going through a momentary financial crisis? The answer, on which depend the actual probability of the PV systems diffusion and the achievement of the "20-20-20" targets, implies a twofold study:

1) the accurate evaluation of the solar potential, PV generation and electricity demand considering all aspects that make the problem more complex in urban areas (different slanted and flat roof shapes, actual available surface of roofs, sizes of PV systems referred to the number of co-owners of the same roof, shading obstructions, mismatch between generated and consumed energy);

2) the economic profitability of the investment according to the change in the values of the economic parameters involved in the analysis (price of PV technology, price of electricity, discount rate) and the financial incentives adopted by governments.

First, the paper assesses the electrical production of a study area by means of some delineating housing types that are peculiar to a district of an Italian southern city; then the paper surveys all factors involved in the profitability of the economic investment and plunges into the development of their monthly variations. Eventually, the effects on the coverage of district energy demand and the economic profitability of PV systems are discussed.

\section{The methodology}

The methodology used in the case study, which was fully described by Cellura et al. [40], assessed the photovoltaic potential of a selected urban area using Google Earth ${ }^{\mathrm{TM}}$ and Street View tool 


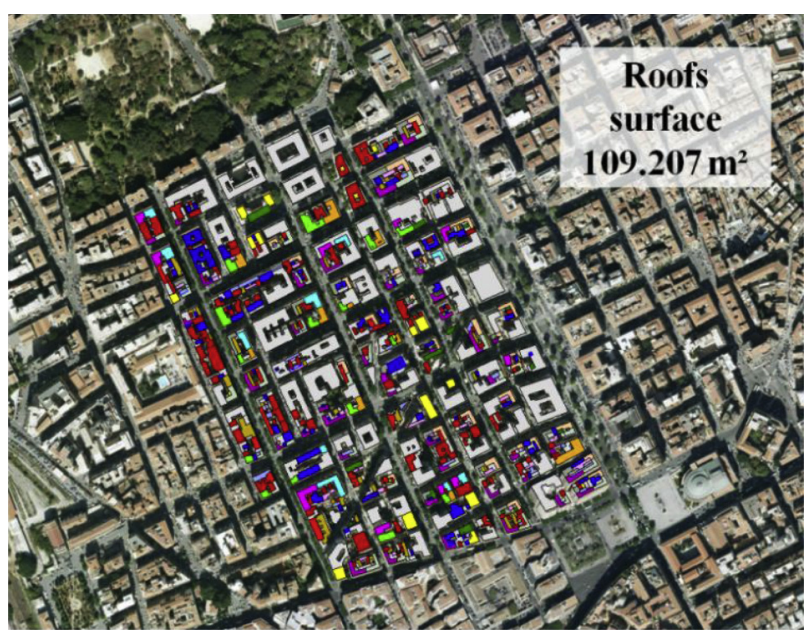

Fig. 1. The area of district occupied by buildings.

to classify buildings, according to their number of floors, shape, orientation and pitch of roofs. The coverage of the electricity demand was evaluated by combining the consumption of electricity of the households and the electrical generation produced by the PV systems that resulted economically convenient on the basis of advantageous values of the NPV (net present value) or the IRR (internal rate of return). In this study the economic analysis was carried out over the period from June 2010 to August 2012 considering the monthly changes of the parameters that mainly influence computations.

The methodology proposed by Cellura et al. goes through the following steps:

Energy assessment:

- identification of buildings of the district;

- estimation of number of floors and flats of each building;

- identification of slanted tiled roofs and flat roofs;

- shape classification of roofs;

- identification of roof surfaces available for PV systems;

- evaluation of the roof surface available for each flat;

- design of the PV system for each flat;

- estimation of solar energy collected by the PV system during its lifetime;

- estimation of the electricity produced by the PV system during its lifetime;

- estimation of the electricity consumed by the owner of each flat during day and night.

\section{Economic assessment:}

- evaluation of costs of PV system devices during its lifetime;

- evaluation of costs for maintenance, servicing and insurance against damage during PV system lifetime;

- estimate of value of electricity produced by the PV system during its lifetime;

- estimate of cost of electricity consumed by the owner of the flat during PV system lifetime;

- estimate of value of sold electricity produced by the PV system during lifetime;

- estimate of value of incentives during PV system lifetime;

- estimate of values of significant financial parameters (inflation rate, weighted average cost of capital, change in the prices of electricity and PV devices, etc);

- evaluation of financial analysis indicators (net present value, internal rate of return, pay-back period);

\begin{tabular}{ll}
\hline - Slanted roofs: & $60,145 \mathrm{~m}^{2}(55.07 \%)$ \\
- Flat roofs: & $37,902 \mathrm{~m}^{2}(34.71 \%)$ \\
- Terraces: & $11,017 \mathrm{~m}^{2}(10.09 \%)$ \\
- Others: & $143 \mathrm{~m}^{2}(0.13 \%)$ \\
\hline
\end{tabular}

- assessment of the feasibility of the PV system;

- exclusion of the roofs that are economically unsuitable;

- evaluation of all economically suitable roofs of the district;

- sensitivity analysis applied to most significant physical and economic parameters.

\section{Energy analysis}

A definite urban scenario was assumed to calculate the produced annual PV electricity. In particular, the study was carried out for a district of Palermo (Sicily - Italy), which is shown in Fig. 1.

The district is characterized by medium and high density residential urban morphology types. The district area occupied by the buildings covers $38.2 \%$ of the gross district surface. The buildings have a regular and straight orientation ( $117^{\circ}$ East of South and $153^{\circ}$ West of South). The surveyed surfaces are subdivided as follow:

By using software Google Earth ${ }^{\mathrm{TM}}$, the slanted and flat roofs were matched with the number of floors of each building.

As it is shown in Fig. 2, most of the roofs cover buildings of four floors; the majority of the slanted roofs belong to buildings of four floors whereas most of the flat roofs cover buildings of eight floors.

\subsection{PV systems power generation}

The yearly electricity produced by the PV systems potentially installed on the roofs was calculated according to the roof surface available for the co-owners of each building. While on a flat roof the orientation and pitch of the PV panels can be chosen independent from the orientation of the building to achieve the highest energy production, the PV panels located on slanted roofs are often installed with the same orientation and pitch of the roof. The PV panels installed on slanted roofs rarely have the optimal values of orientation and pitch; moreover the presence of triangular surfaces, typical of slanted hip roofs, reduces the area of roof exploitable for the installation of PV modules. An effective classification of the roof surfaces may reduce the amount of calculations that are necessary to design the PV systems to be installed on the roof of each building. Such a classification requires different approaches for slanted and flat roofs.

The buildings with slanted roofs were built before the Second World War according to the structural standard, which was characterized by masonry walls, with a $30-60 \mathrm{~cm}$ thickness range,

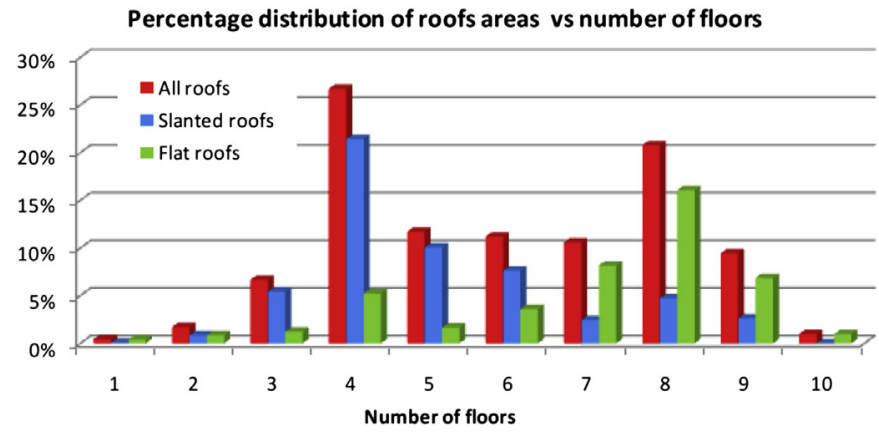

Fig. 2. Distribution of roof areas versus number of floors. 
Table 1a

Elementary slanted roof shapes.

\begin{tabular}{lllll}
\hline $\mathrm{A}$ & $\mathrm{B}$ & $\mathrm{C}$ & $\mathrm{D}$ & $\mathrm{E}$ \\
\hline & & \\
\hline
\end{tabular}

distant each other about $4-5 \mathrm{~m}$; the buildings have a standard depth of about $9 \mathrm{~m}$. Each flat has an entrance hall, a corridor, 5-6 rooms, a kitchen and bathrooms; the estimated gross surface is of about $150-170 \mathrm{~m}^{2}$. For calculations it was assumed that each flat had a standard surface of $162 \mathrm{~m}^{2}$ and a fixed dimension (width or length) of $9 \mathrm{~m}$. To make a significant comparison, the same size was assumed for flats of the buildings with flat roofs.

The slanted roof of many buildings looks like a complex composition of different elementary roof shapes such as gable, hip and skillion. Some buildings have roofs orthogonally joined; besides, the buildings can have different orientations. For a generic district characterized by a regular square layout of streets and a well ordered orientation of buildings, the 5 types of elementary shapes shown in Table 1a have been identified (the arrows in the drawings indicate the slope direction).

Types A and B are gable roofs, type $C$ is a hip roof and types D and $E$ are skillion roofs. The elementary roof types of Table $1 \mathrm{a}$ should be rotated to consider all the different orientations of buildings. Depending on the local building traditions, some other kinds of roof shapes may be obviously considered. Table 1b shows the elementary roof types used to classify the roofs of the district.

The classification of the slanted roof is a painstaking procedure that is necessarily affected by some amount of approximation. It is based on the following steps, which have to be repeated for each building of the district:

1) Measurement of the global surface of the building roof, using the images provided by Google Earth ${ }^{\mathrm{TM}}$;

2) Calculus of the approximate number of standard flats that can be contained in the floor, dividing the global roof surface by the flat standard surface $\left(162 \mathrm{~m}^{2}\right)$;

3) Assessment of the number of floors of the building, using Street View;

4) Calculus of the number of co-owners, which in turn corresponds to the number of PV systems that may be installed on the building roof;

5) Division of the building roof in portions obtained by approximating the roof shape with one, or more, of the roof types of Table $1 \mathrm{~b}$

6) Measurement of the surface of each portion of the roof;
Table 2

Surface area of slanted roofs.

\begin{tabular}{llc}
\hline Roof type & Surface area $\left[\mathrm{m}^{2}\right]$ & Surface area $[\%]$ \\
\hline T1 & 8162 & 13.57 \\
T2 & 12,901 & 21.45 \\
T3 & 2690 & 4.47 \\
T4 & 2031 & 3.38 \\
T5 & 2144 & 3.56 \\
T6 & 2219 & 3.69 \\
T7 & 1582 & 2.63 \\
T8 & 2880 & 4.79 \\
T9 & 2296 & 3.82 \\
T10 & 1683 & 2.80 \\
T11 & 3298 & 5.48 \\
T12 & 2906 & 4.83 \\
T13 & 3787 & 6.30 \\
T14 & 3765 & 6.26 \\
T15 & 3618 & 6.02 \\
T16 & 4183 & 6.95 \\
Total & 60,145 & 100.00 \\
\hline
\end{tabular}

7) Classification of each roof portion by recording the surface, the associated roof type (T1-T16) and the number of floors covered by the portion of the roof.

Table 2 lists the surface area of the slanted roofs.

A less complex criterion was used to classify flat roofs because in this case the shape of the roof and the orientation of the building marginally affect the design and the energy efficiency of the PV system; if the buildings were rotated in order to result to be south facing, the PV arrays averagely would increase of $5.1 \%$. The solar potential of flat roofs, where PV panels can be oriented to south and installed with the most advantageous tilt angle, mainly depends on the size of the PV field, which in turn is related to the area of the roof that is available for installation. The ratio of the area available for installation to the gross roof surface may vary with the size of the roof; actually the shading effects due obstructions (balustrades, elevator housings, HVAC (Heating, Ventilation and Air conditioning) equipment, water tanks etc.) are relatively less evident in large roofs, whereas the area available for installation in small roofs may be drastically reduced. For this reason, and also considering that the number of the surveyed buildings with flat roofs only permitted to create few classes with a significant statistical population, flat roofs were sorted by their size and clustered in five classes. Once evaluated the area mean value of each class, five buildings of the district were selected to represent each class (Table 3). The selected buildings have a roof area close to the area mean value of the flat roof class that they represent. The results are summarized in Table 4.

The above methodology, which is sensitive to the different urban morphologies may be considered a sort of flexible guideline

Table 1b

Classification of roof shapes.

T9
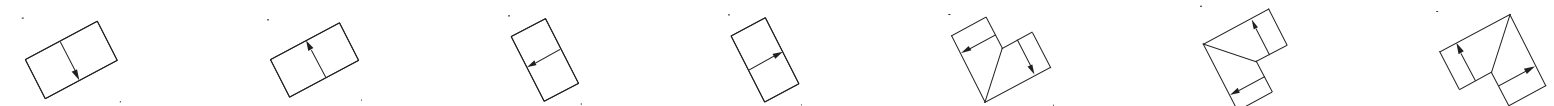
Table 4

Surface area of flat roofs.

\begin{tabular}{llc}
\hline Roof type & Surface area $\left[\mathrm{m}^{2}\right]$ & Surface area [\%] \\
\hline FR1 & 3065 & 8.09 \\
FR2 & 4267 & 11.26 \\
FR3 & 5501 & 14.51 \\
FR4 & 9235 & 24.37 \\
FR5 & 15,834 & 41.77 \\
Total & 37,902 & 100.00 \\
\hline
\end{tabular}

that should be properly calibrated selecting the roof types that are indicative of regional building customs. It is probable that a different number of roof types will have to be selected in a different situation according to the peculiarities of the analysed city.

The electricity produced by slanted and flat roofs was estimated considering that the PV fields were built with commercial PV panels (Kyocera KD210GH-2PU), whose dimensions are $1.50 \times 0.99 \mathrm{~m}$. To size the PV fields each roof area was divided by the number of floors and flats of the building. The electricity calculations were repeated for each type of roof and each number of floors using the software PVsyst 5.06 [41] that includes monthly data of the global irradiation, temperatures and wind velocity (Meteonorm, versions $4-5$ ). The result of each power calculation was divided by the area of the standard flat in order to evaluate the specific value of electricity production for square metre to be accredited to any flat located in a building with any number of floors and type of roof. Such a specific value of electricity production obviously varied with the number of floors and roof type. The electricity produced by each building was evaluated by multiplying the specific value of the electricity production by the global area of the flats of the building. The electricity produced by the entire district was calculated by summing the electrical energy produced by all buildings of the district.

For slanted roofs it was also assumed that PV panels were collocated with the same pitch of the roof surface (the pitch of slanted roofs is approximately $25^{\circ}$ above the horizontal), obeying to the rules imposed by Italian government in order to respect aesthetical and architectonic standards. In Table 5 some results of the energy estimation are listed.

For flat roofs it was assumed that PV panels were oriented to the South with a pitch of $30^{\circ}$, which was verified to be the most efficient for the city of Palermo, and installed on the roofs of the buildings of Table 3; the shadowing effect due to balustrades, elevator housings and other obstructions was also considered. In order to get a significant comparison between the energy generation of flat and slanted roofs, the PV fields sized for the roof area of each representative buildings of Table 3 were resized in order to harness the area at disposal of the standard flat $\left(162 \mathrm{~m}^{2}\right)$. The results are shown in Table 6 .

Table 5

Electricity produced by slanted roofs.

\begin{tabular}{lll}
\hline Number of floors & Total roofs area $\left(\mathrm{m}^{2}\right)$ & Electricity produced $(\mathrm{kWh} / \mathrm{year})$ \\
\hline 1 & 64 & 5266.96 \\
2 & 934 & $41,300.53$ \\
3 & 5923 & $149,476.55$ \\
4 & 23,316 & $512,594.78$ \\
5 & 10,947 & $163,643.40$ \\
6 & 8320 & $784,56.53$ \\
7 & 2658 & $224,70.96$ \\
8 & 5158 & $44,347.64$ \\
9 & 2825 & $10,223.05$ \\
Total & 60,145 & $1,027,780.40$ \\
\hline
\end{tabular}

Table 6

Electricity produced by flat roofs.

\begin{tabular}{lll}
\hline Number of floors & Total roofs area $\left(\mathrm{m}^{2}\right)$ & Electricity produced $(\mathrm{kWh} /$ year $)$ \\
\hline 1 & 0 & 0.00 \\
2 & 0 & 0.00 \\
3 & 0 & 0.00 \\
4 & 2319 & $43,090.88$ \\
5 & 320 & 3014.04 \\
6 & 3581 & $45,646.84$ \\
7 & 8011 & $89,973.85$ \\
8 & 15,911 & $165,323.55$ \\
9 & 6718 & $55,099.39$ \\
10 & 1042 & 7572.44 \\
Total & 37,902 & $409,721.00$ \\
\hline
\end{tabular}

\subsection{Coverage of the electricity demand}

To estimate the amount of electricity produced by PV systems that covers the energy demand of the district the following gross energy cover factor $C_{\mathrm{PV}}$ was used:

$C_{\mathrm{PV}}=\frac{\sum_{j=1}^{N_{\mathrm{PV}}} E_{\mathrm{PV}, j}^{*}}{\sum_{j=1}^{N_{\mathrm{PV}}} D_{j}^{*}} \cdot 100=\frac{E_{\mathrm{PVTotal}}}{D_{\text {Total }}} \cdot 100$

where $N_{\mathrm{PV}}$ represents the number of PV systems of the district and $E_{\mathrm{PV}, j}^{*}$ is the yearly PV generation of the $j$-th PV system of the district; $D_{j}^{*}$ is the power demand of the $j$-th flat. $E_{\text {PVTotal }}$ and $D_{\text {Total }}$ are the total yearly PV generation and demand of the district, respectively.

Assuming the data officially issued by TERNA [42], main Italian electricity transmission grid operator, and ISTAT, Italian National Institute of Statistics [43], which are listed in Table 7, it was estimated that a household of 5.02 persons live in a standard flat of $162 \mathrm{~m}^{2}$ and averagely consumes $5957.3 \mathrm{kWh}$ every year.

The results of the calculations of energy cover factor $C_{\mathrm{PV}}$ performed by means of Eq. (1) are shown in Fig. 3.

PV system generation is $35.8 \%$ of the district electricity demand; the energy production is mainly due to the sloped roofs covering buildings of four floors.

If the energy generated by a PV system is greater than the electricity demand of the flat, a part of the electrical production will be exported to the grid. Moreover, because the instantaneous perfect correspondence between demand and generation is quite improbable, a part of the demanded electricity may be not covered by the PV generation even if the energy generated is greater than the electricity demand. To better understand the importance of the mismatch between generated and consumed electricity, it is useful to refer to Fig. 4 where the $j$-th PV system of the district is sketched; batteries are not considered.

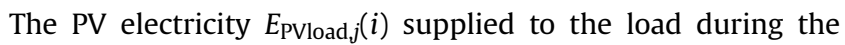
generic $i$-th time interval is:

$E_{\text {PVload }, j}(i)=\min \left[E_{\mathrm{PV}_{j}, j}(i), D_{j}(i)\right]$

in which $E_{\mathrm{PV}}(i)$ and $D_{j}(i)$ are the PV electricity and the demand, respectively. When the PV electricity and the electrical demand do

Table 7

Energy and statistic figures for Palermo.

\begin{tabular}{ll}
\hline Electricity consumption in Palermo's province & $1475.80 \mathrm{GWh} /$ year \\
Area of inhabited flats in Palermo & $22,141,320 \mathrm{~m}^{2}$ \\
Number of inhabitants in Palermo's province & $1,244,680$ \\
Number of inhabitants in Palermo & 686,711 \\
\hline
\end{tabular}


Table 3

Classification of flat roofs.

\begin{tabular}{lllll}
\hline FR1 & FR2 & FR3 & FR4 & FR5 \\
$265 \mathrm{~m}^{2}$ & $387 \mathrm{~m}^{2}$ & $482 \mathrm{~m}^{2}$ & $717 \mathrm{~m}^{2}$ & $1394 \mathrm{~m}^{2}$ \\
\hline
\end{tabular}

not perfectly match each other, some amount of electricity is exchanged with the grid:

$E_{\mathrm{PV}, j}(i)=E_{\mathrm{PVload}, j}(i)+E_{\exp , j}(i)$

$D_{j}(i)=E_{\text {PVload }, j}(i)+E_{\text {imp }, j}(i)$

where exported electricity $E_{\exp , j}(i) \neq 0$, if $E_{\mathrm{PV}, j}(i)>D_{j}(i)$; conversely imported electricity $E_{\text {imp } j}(i) \neq 0$, if $E_{\mathrm{PV}_{j}}(i)<D_{j}(i)$. Obviously if $E_{\text {exp }, j}(i) \neq 0$ then $E_{\text {imp } j}(i)=0$, and vice versa, during the same time interval.

In order to consider the effect of the mismatch between generated and consumed electricity, many load matching indicators have been proposed. The ratio of the PV electricity supplied to the load and the electrical demand was named the solar fraction by Widén et al. [44], the load match index by Voss et al. [45], and the cover factor by Verbruggen et al. [46]. Such a parameter, which represents the percentage of the electrical demand that is covered by the generation of the $j$-th PV system over period $T$, can be calculated with the following equation:

$\gamma_{\mathrm{D}, j}=\frac{\sum_{i}^{i+N} \min \left[E_{\mathrm{PV}, j}(i), D_{j}(i)\right]}{\sum_{i}^{i+N} D_{j}(i)} \cdot 100=\frac{E_{\mathrm{PVload}, j}^{*}}{D_{j}^{*}}$

in which $N$ is the number of samples in the considered evaluation period $T$. $E_{\mathrm{PVload}, j}^{*}$ and $D_{j}^{*}$ are the PV electricity supplied to the load and the electrical demand of the $j$-th PV system over the evaluation period, respectively. The accurate evaluation of load match index $\gamma_{\mathrm{D} j}$ requires a dynamic approach based on the knowledge of the daily distribution of the electricity generation and demand.

If a day is assumed for the generic $i$-th time interval, load match index $\gamma_{D}$ calculated with Eq. (5) corresponds to the condition under which, if the PV generation is sufficient, the daily energy demand is always covered by the PV electricity. Such an optimistic condition is quite unreal because it involves a perfect simultaneity between PV

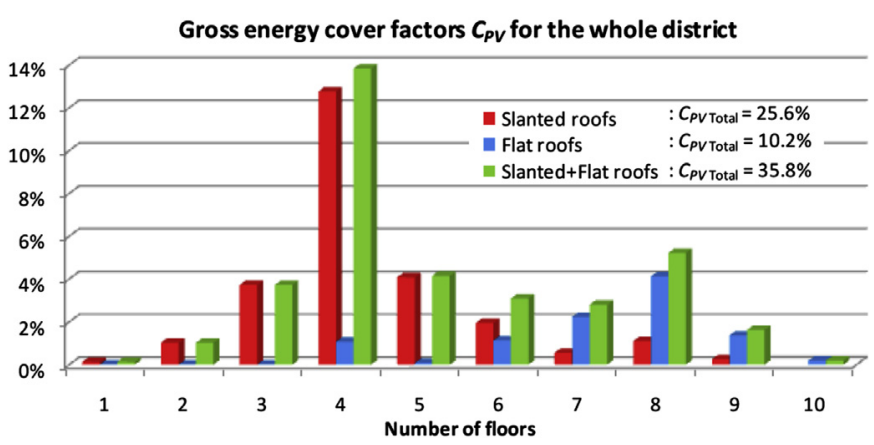

Fig. 3. Yearly gross energy cover factors for the whole district, versus the number of floors.

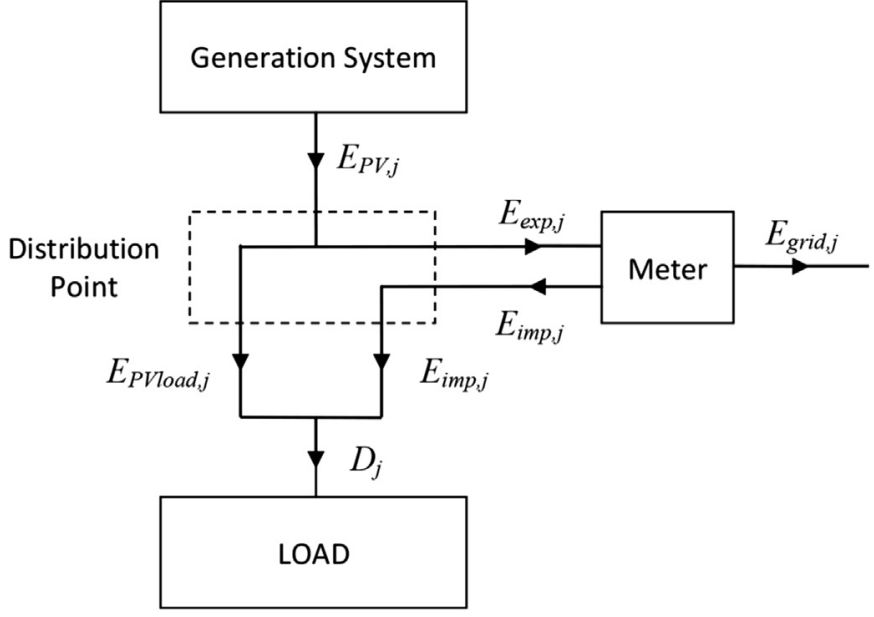

Fig. 4. Sketch of the energy exchanges in a PV systems without batteries.

generation and consumption. Actually, even adopting the best strategy to exploit the PV generation, the electricity $D_{\text {Night }}$ consumed after sunset and before dawn will be never compensated by the energy produced by a grid-connected PV system that does not use batteries. Therefore, to correctly assess the economic convenience, a minimum mismatch between generated and consumed electricity has to be always considered.

To estimate night demand $D_{\mathrm{Night}, j}$ it was assumed that the following appliances were working in the standard flat [47-50], from dusk to dawn:

Because the electricity generated by the PV system is quite small at the beginning and at the end of the day, $T_{\mathrm{i}}$ was assumed $1 \mathrm{~h}$ before sunset time and $T_{\mathrm{f}} 1 \mathrm{~h}$ after dawn time; sunset and dawn time in Palermo on 15th of each month were considered. It was calculated a $D_{\text {Night }, j}$ of $716.5 \mathrm{kWh} /$ year and consequently the day energy demand $D_{\text {Day } j}=5240.8 \mathrm{kWh} /$ year. As a consequence $12 \%$ of the consumed electricity is never supplied by the PV systems and $\gamma_{D}$ will never surpass $88 \%$.

When only the yearly energy data are available, load match index $\gamma_{D}$ of the district may be evaluated with the approximate expression:

$\gamma_{\mathrm{D}}=\frac{\sum_{j}^{N_{\mathrm{PV}}} \min \left[E_{\mathrm{PV}, j}^{*}, D_{j}^{*}\right]}{\sum_{j}^{N_{\mathrm{PV}}} D_{j}^{*}} \cdot 100$

where it was assumed that:

$$
\begin{aligned}
& \sum_{j}^{N_{\mathrm{PV}}} \sum_{i}^{i+N} \min \left[E_{\mathrm{PV}, j}(i), D_{j}(i)\right] \approx \sum_{j}^{N_{\mathrm{PV}}} \min \left[\sum_{i}^{i+N} E_{\mathrm{PV}, j}(i), \sum_{i}^{i+N} D_{j}(i)\right] \\
& =\sum_{j}^{N_{\mathrm{PV}}} \min \left[E_{\mathrm{PV}, j}^{*}, D_{j}^{*}\right]
\end{aligned}
$$

In Fig. 5 the yearly load match indexes of the district are displayed.

\begin{tabular}{lll}
\hline - Lamps: & $85 \mathrm{~W}$ & From $T_{i}$ to $23: 00-$ from 07.00 to $T_{\mathrm{f}}$ \\
- Refrigerator: & $90 \mathrm{~W}$ & From $T_{i}$ to $24: 00-$ from 00.00 to $T_{\mathrm{f}}$ \\
- Television + P.C.: & $75 \mathrm{~W}$ & From $T_{i}$ to 23:00 - from 07.00 to $T_{\mathrm{f}}$
\end{tabular}


Load match indexes $\gamma_{D}$ for the whole district

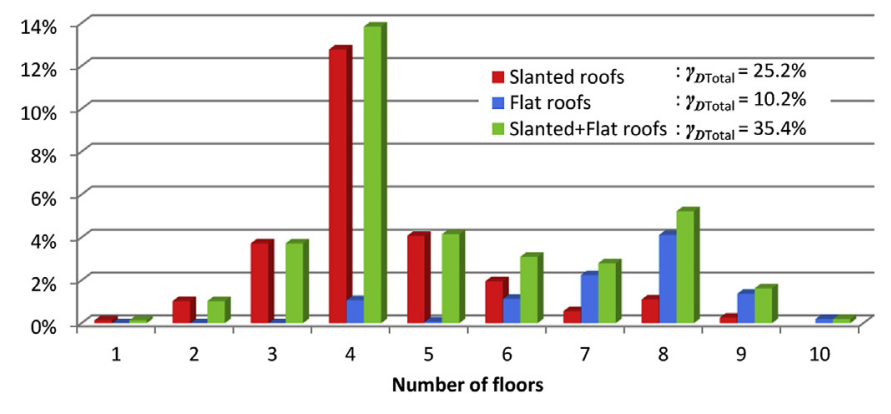

Fig. 5. Yearly load match indexes for the whole district, versus the number of floors.

PV system generation that is supplied to the load is $35.4 \%$ of the district electricity demand. The small difference between the gross energy cover factor and the load match index confirms the fact that the PV generation of the systems installed on the roofs of buildings of one and two floors exceeds the corresponding electricity demand.

\section{Economic analysis}

With the aim of calculating the actual values of the gross energy factor and load match index of the district, the PV electricity generated by PV systems has to be associated with the economic analysis. This approach provides an important guidance to the householders who are planning to invest in a PV system. Actually, even if the energy coverage of the demand is guaranteed, the initial costs of the PV devices may be not covered. On the other hand, even if the electrical production does not completely satisfy the energy demand, anyway the investment may result profitable.

In order to estimate the actual feasibility of the PV investment during the time, the net present value (NPV), internal rate of return (IRR) and payback period, which are indicators commonly applied to evaluate the investment advantage, were analysed. To calculate the IRR and NPV of each investment with a cash flow $C_{\mathrm{t}}$ related to the generic $t$-th year the following formulae were used:

$\mathrm{NPV}=\sum_{t=1}^{N_{t}} \frac{C_{t}}{(1+k)^{t}}-C_{0}$

$C_{0}-\sum_{t=1}^{N_{t}} \frac{C_{t}}{(1+\mathrm{IRR})^{t}}=0$
Relative variation of incentives

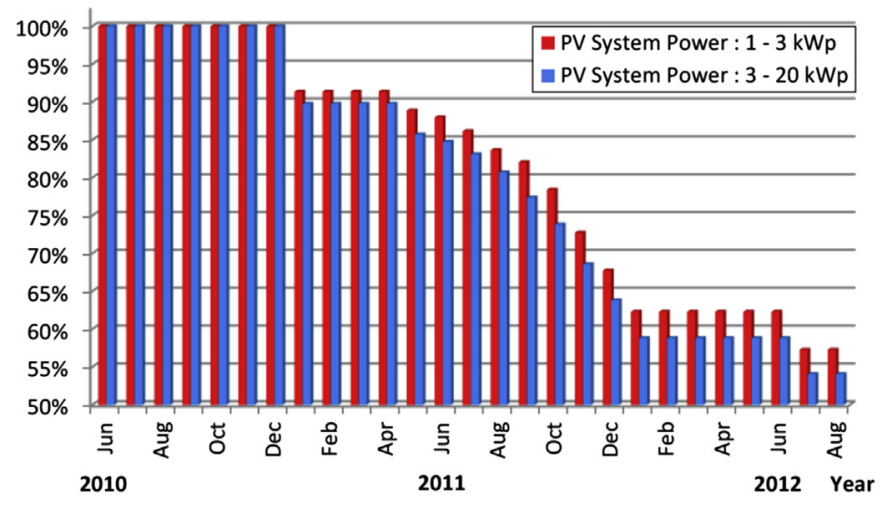

Fig. 6. Incentives relative variation during the analysed period.

where $N_{t}$ is the lifetime of the investment, $C_{0}$ is the initial investment cost and $k$ is the discount rate, which is the index that represents the average expected return on the assets of the owner of the system. The above indicators are significantly affected by many economic parameters, among which the most important are:

- the value of the incentives;

- the cost of the investment;

- the discount rate;

- the electricity mismatch.

With the aim of considering the influence of the time variation of the ruling parameters involved in the economic analysis, a review of the main parameters is carried out in the following sections.

\subsection{The 2010-2012 PV incentives scheme}

Italian government aimed to support PV systems with 20 years guaranteed FIT for every kWh of produced electricity according to the size of the PV systems. The main characteristic of the Italian incentive scheme consists in adopting a FIT de-escalation during the time. In the present study, in accordance with the tariffs issued by the Ministerial Decree 19 February 2007, a digression rate of $2 \%$ was operated every six months starting from February 2007 [51]. The Ministerial Decree 6 August 2010 imposed new tariffs starting from January 2011 [52]. These tariffs, which changed every four months, were applied until May 2011. Finally, the current Ministerial Decree 5 May 2011 has established that the tariffs de-escalate every month for the period June-December 2011 and fixed values

Table 8

Incentives for electricity generated by PV systems in Italy.

\begin{tabular}{|c|c|c|c|c|c|c|}
\hline \multirow{2}{*}{$\begin{array}{l}\text { Rated power (RP) } \\
{[\mathrm{kWp}]}\end{array}$} & \multicolumn{6}{|c|}{ Value of incentives [ $€ / \mathrm{kWh}]$} \\
\hline & Jun. $\div$ Dec. 2010 & Jan. $\div$ Apr. 2011 & May 2011 & June 2011 & July 2011 & August 2010 \\
\hline $1 \leq \mathrm{RP} \leq 3$ & 0.422 & 0.402 & 0.391 & 0.387 & 0.379 & 0.368 \\
\hline $3<\mathrm{RP} \leq 20$ & 0.403 & 0.377 & 0.360 & 0.356 & 0.349 & 0.339 \\
\hline $20<\mathrm{RP} \leq 200$ & 0.384 & 0.358 & 0.341 & 0.338 & 0.331 & 0.321 \\
\hline $200<\mathrm{RP} \leq 1000$ & 0.384 & 0.355 & 0.335 & 0.325 & 0.315 & 0.303 \\
\hline $1000<\mathrm{RP} \leq 5000$ & 0.384 & 0.351 & 0.327 & 0.314 & 0.298 & 0.280 \\
\hline $\mathrm{RP}>5000$ & 0.384 & 0.333 & 0.311 & 0.299 & 0.284 & 0.269 \\
\hline$[\mathrm{kWp}]$ & September 2011 & October 2011 & November 2011 & December 2011 & 1st half year 2012 & 2nd half year 2012 \\
\hline $1 \leq \mathrm{RP} \leq 3$ & 0.361 & 0.345 & 0.320 & 0.298 & 0.274 & 0.252 \\
\hline $3<\mathrm{RP} \leq 20$ & 0.325 & 0.310 & 0.288 & 0.268 & 0.247 & 0.227 \\
\hline $20<\mathrm{RP} \leq 200$ & 0.307 & 0.293 & 0.272 & 0.253 & 0.233 & 0.214 \\
\hline $200<\mathrm{RP} \leq 1000$ & 0.298 & 0.285 & 0.265 & 0.246 & 0.224 & 0.202 \\
\hline $1000<\mathrm{RP} \leq 5000$ & 0.278 & 0.256 & 0.233 & 0.212 & 0.182 & 0.164 \\
\hline $\mathrm{RP}>5000$ & 0.264 & 0.243 & 0.221 & 0.199 & 0.171 & 0.154 \\
\hline
\end{tabular}


for both semesters 2012 [53]. The values of incentives are listed in Table 8.

The relative variation of incentives over the period from June 2010 to August 2012 is displayed in Fig. 6; data refer to the rated power up to $20 \mathrm{~kW}$, which is the value never exceeded by the PV systems sized in this study.

The feed-in tariffs used in the economic calculations were updated every month taking account of the rated power of PV systems. It is evident that the noticeable reduction in the FIT may discourage householders from investing in PV systems if the trend of the costs of PV devices, which is depicted in the next section, had not a progressive and steady decrease.

\subsection{Cost of the investment}

In order to get an accurate estimate of the investment cost it is necessary to examine all components involved: PV panels, inverters, main switchboards, cabling, connectors, mounting systems, etc. Costs were deduced from the market prices of components, also charging the cost for labour and fitter's gain. The change in prices of the devices that are more subject to the market fluctuations are is displayed in Fig. 7.

As it can be observed in Fig. 7, there is a substantial difference between trends of the price of panels, inverters and copper wire. The histogram, which was depicted on the basis of issued data [54,55], shows that the variation of module prices have been continuously decreasing from June 2010 to August 2012 with an average annual drop of $20 \%$. Inverters had a discontinuous variation of price with an upward trend starting from May 2011. As usually happens during financial crises, copper wire has been rapidly increasing since June 2010.

\subsection{Discount rate}

Investment decisions require the estimates of the investment costs, economic life of the investment, and cash flows. As mentioned in the previous section, the results of this assessment are commonly expressed by means of the indicators, such as the NPV and IRR. These parameters, which assess the actual feasibility of the PV investment during the time, require complex computations and detailed knowledge of the main aspects of the economic sector.

The discount rate, also known as return on investment or rate of profit, is the interest divided by the capital including that interest. The discount rate can be used to estimate the actual feasibility of the PV investment because it represents the rate of return that

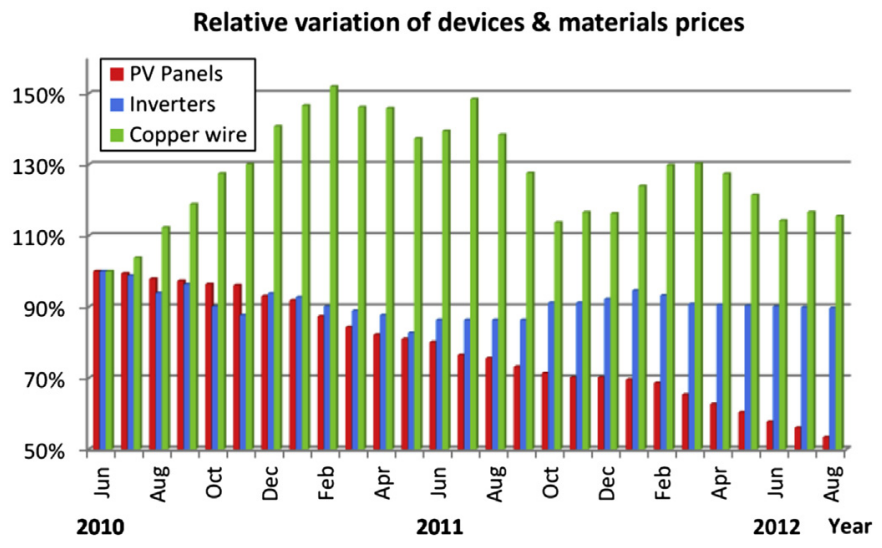

Fig. 7. Relative variation of devices and materials prices during the analysed period. could be earned from an investment in the financial markets with similar risk. The return on capital employed in Italian long term public securities, a risk-free financial activity [56], was used for calculations. Financial and monetary crisis gave rise to a leap in the paid interest. Fig. 8 shows the deviations of the index starting from June 2010 to August 2012.

The highest values of the index in November and December 2011 bear witness to the dramatic lack of stability of the current Italian market. An index increase denotes a high level of economic risk that puts secure investments in jeopardy. This condition is crucial for the decisions of PV investors because also the incentives paid by the government of a country that is going through a solvency crisis may be considered untrustworthy.

\subsection{Mismatch}

In order to assess the impact of the mismatch on the district load match index, a sensitivity analysis has been carried out on the basis of the available yearly energy data. To reach the purpose it is useful to split the energy demand of the generic $j$-th PV system as described below:

$D_{j}^{*}=D_{\text {Day }, j}+D_{\text {Night }, j}=D_{\text {Match }, j}+D_{\text {Mism }, j}$

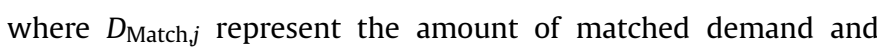
$D_{\mathrm{Mism}, j}$ is the amount of mismatched demand. Let us assume that $D_{j}$ is constant (5957.3 $\mathrm{kWh} /$ year) and that $D_{\text {Match } j}$ varies from 0 to $D_{\text {Day } j}(5240.8 \mathrm{kWh} /$ year) as a consequence of the smart use of the electrical appliances:

$D_{\text {Match }, j}\left(c_{\mathrm{u}}\right)=c_{\mathrm{u}} D_{\text {Day } j} j$

where utilization coefficient $c_{\mathrm{u}}$ :

$c_{\mathrm{u}}=\frac{D_{\text {Match } j}}{D_{\text {Day } j}}$

varies from 0 (no PV generation used) to 1 (maximum PV generation used). The constant yearly demand can be rewritten as:

$D_{j}^{*}=D_{\text {Match }, j}\left(c_{\mathrm{u}}\right)+D_{\mathrm{Mism}, j}\left(c_{\mathrm{u}}\right)=E_{\mathrm{PVload}, j}^{*}\left(c_{\mathrm{u}}\right)+E_{\mathrm{imp}, j}^{*}\left(c_{\mathrm{u}}\right)$

where $E_{\mathrm{imp}, j}^{*}\left(c_{\mathrm{u}}\right)$ is the yearly imported electricity of the $j$-th PV system of the district and $E_{\mathrm{PVload}, j}^{*}\left(c_{\mathrm{u}}\right)$, which represents the PV

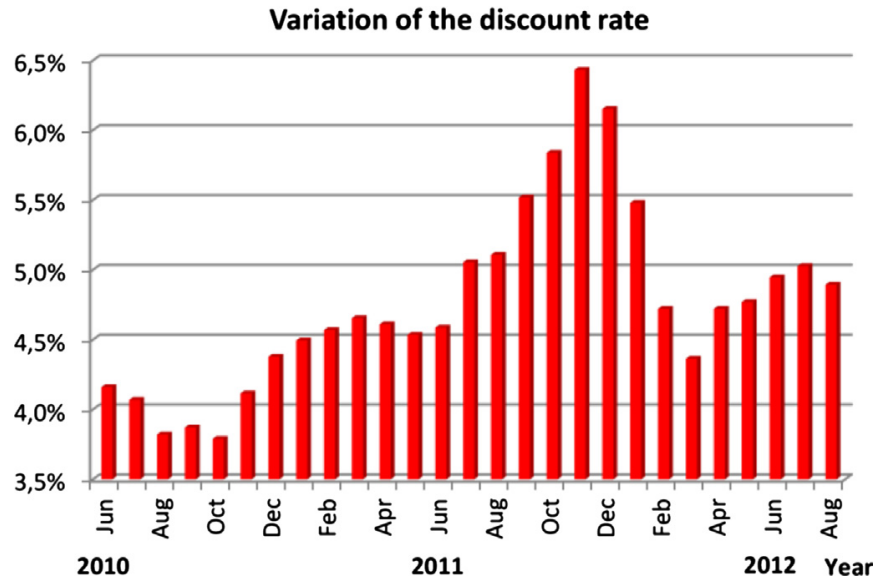

Fig. 8. Variation of the discount rate during the analysed period. 
Table 9

Monthly variation of main economic parameters.

\begin{tabular}{|c|c|c|c|c|c|c|}
\hline \multirow[t]{2}{*}{ Month } & \multicolumn{3}{|c|}{ Relative variation [\%] } & \multicolumn{2}{|c|}{$\begin{array}{l}\text { Last } 120 \text { months average } \\
\text { variation [\%] }\end{array}$} & \multirow[t]{2}{*}{$\begin{array}{l}\text { Discount } \\
\text { rate [\%] }\end{array}$} \\
\hline & $\begin{array}{l}\text { Panels } \\
\text { price }\end{array}$ & $\begin{array}{l}\text { Inverters } \\
\text { price }\end{array}$ & $\begin{array}{l}\text { Copper } \\
\text { price }\end{array}$ & $\begin{array}{l}\text { Inflation } \\
\text { rate }\end{array}$ & $\begin{array}{l}\text { Electricity } \\
\text { price }\end{array}$ & \\
\hline June 2010 & 8.852 & 7.821 & -31.801 & 2.016 & 5.651 & 4.160 \\
\hline July 2010 & 8.197 & 6.518 & -29.189 & 2.035 & 5.476 & 4.068 \\
\hline Aug. 2010 & 6.557 & 1.304 & -23.397 & 2.057 & 5.476 & 3.820 \\
\hline Sep. 2010 & 5.902 & 3.911 & -18.919 & 2.010 & 5.476 & 3.870 \\
\hline Oct. 2010 & 4.918 & -2.793 & -13.043 & 2.005 & 5.355 & 3.789 \\
\hline Nov. 2010 & 4.590 & -5.400 & -11.274 & 1.968 & 5.355 & 4.115 \\
\hline Dec. 2010 & 1.311 & 1.117 & -3.990 & 1.995 & 5.355 & 4.378 \\
\hline Jan. 2011 & 0.000 & 0.000 & 0.000 & 1.976 & 5.203 & 4.495 \\
\hline Feb. 2011 & -4.918 & -2.793 & 3.648 & 1.971 & 5.203 & 4.569 \\
\hline Mar. 2011 & -8.197 & -4.097 & -0.313 & 2.001 & 5.203 & 4.655 \\
\hline Apr. 2011 & -10.492 & -5.400 & -0.529 & 2.016 & 5.187 & 4.611 \\
\hline May 2011 & -11.803 & -10.801 & -6.310 & 1.999 & 5.187 & 4.535 \\
\hline June 2011 & -12.787 & -6.890 & -4.892 & 1.992 & 5.187 & 4.587 \\
\hline July 2011 & -16.721 & -6.890 & 1.230 & 2.021 & 5.167 & 5.054 \\
\hline Aug. 2011 & -17.705 & -6.890 & -5.614 & 2.050 & 5.167 & 5.108 \\
\hline Sep. 2011 & -20.328 & -6.890 & -12.934 & 2.041 & 5.167 & 5.519 \\
\hline Oct. 2011 & -22.295 & -1.676 & -22.437 & 2.054 & 5.188 & 5.838 \\
\hline Nov. 2011 & -23.607 & -1.676 & -20.478 & 2.046 & 5.188 & 6.433 \\
\hline Dec. 2011 & -23.607 & -0.559 & -20.710 & 2.067 & 5.188 & 6.152 \\
\hline Jan. 2012 & -24.262 & 2.048 & -15.433 & 2.062 & 5.123 & 5.480 \\
\hline Feb. 2012 & -25.246 & 0.559 & -11.451 & 2.066 & 5.123 & 4.722 \\
\hline Mar. 2012 & -28.852 & -2.048 & -11.143 & 2.079 & 5.123 & 4.364 \\
\hline Apr. 2012 & -31.751 & -2.297 & -13.088 & 2.101 & 5.090 & 4.722 \\
\hline May 2012 & -34.287 & -2.545 & -17.164 & 2.074 & 5.090 & 4.770 \\
\hline June 2012 & -37.186 & -2.793 & -22.080 & 2.076 & 5.090 & 4.946 \\
\hline July 2012 & -38.997 & -3.041 & -20.444 & 2.077 & 5.244 & 5.027 \\
\hline Aug. 2012 & -41.896 & -3.289 & -21.218 & 2.107 & 5.244 & 4.894 \\
\hline
\end{tabular}

electricity supplied to the matched demand $D_{\text {Macth }, j}\left(c_{\mathrm{u}}\right)$, is calculated with the following expression:

$E_{\text {PVload }, j}^{*}\left(c_{\mathrm{u}}\right)=\min \left[E_{\mathrm{PV}, j}^{*}, D_{\mathrm{Match}, j}\left(c_{\mathrm{u}}\right)\right]=\min \left[E_{\mathrm{PV}, j}^{*}, c_{\mathrm{u}} D_{\mathrm{Day}}\right]$

By means of the above equations the load match index of the district can be can be related to utilization coefficient $c_{\mathrm{u}}$ :

$$
\gamma_{\mathrm{D}, \mathrm{u}}=\frac{\sum_{j}^{N_{\mathrm{PV}}} \min \left[E_{\mathrm{PV}, j}^{*}, c_{\mathrm{u}} D_{\mathrm{Day}}\right]}{\sum_{j}^{N_{\mathrm{PV}}} D_{j}^{*}} \cdot 100=\frac{\sum_{j}^{N_{\mathrm{PV}}} E_{\mathrm{PVload}, j}^{*}\left(c_{\mathrm{u}}\right)}{D_{\text {Total }}} \cdot 100
$$

For given values of the electricity demand and PV generation, gross energy cover factor $C_{\mathrm{PV}}$ is not affected by the mismatch. Adversely, load match index $\gamma_{\mathrm{D}, \mathrm{u}}$ is sensitive to mismatch and can be less than $100 \%$ for two different reasons. If the PV systems are undersized to cover the energy demands, then $E_{\mathrm{PV}, j}^{*}<D_{j}^{*}$ and consequently $E_{\mathrm{PVload}, j}^{*}<D_{j}^{*}$. When the PV system is not undersized $\left(E_{\mathrm{PV}, j}^{*}>D_{j}^{*}\right)$ but the generation mismatches the energy demand $\left(c_{\mathrm{u}}<1\right)$, then $E_{\mathrm{PVload}, j}^{*}<D_{j}^{*}$. Even though the PV production perfectly covers the demand $\left(E_{\mathrm{PV}, j}^{*}=D_{j}^{*} \rightarrow C_{\mathrm{PV}}=100 \%\right)$, when $c_{\mathrm{u}}<1$, some amount of energy produced $E_{\mathrm{PV}, j}^{*}$ is not contemporary consumed and consequently it is $\gamma_{\mathrm{D}, \mathrm{u}}<100 \%$. In a grid-connected PV system, which does not use batteries, both the lack of solar radiation and the inadequate use the appliances affect the load match index.
Filtered gross energy cover factors $C_{p v}$ for the whole district

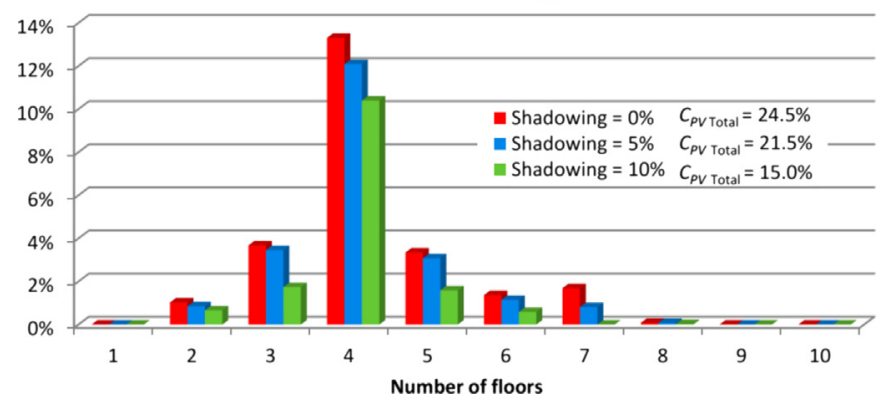

Fig. 9. Yearly gross energy cover factors for the whole district, filtered by the economic assessment, at various values of the shading coefficient versus the number of floors.

\section{Results and discussion}

Starting from June 2010 till August 2012, the cash flow of each PV system was calculated for a period of 20 years assuming the data variations listed in Table 9.

Moreover the following assumptions were considered:

- the yearly degradation rate in the efficiency of the PV panels was set equal to $1 \%$ of the nominal initial value [57].

- the yearly maintenance and management costs was estimated to be $2 \%$ of the investment cost, which is a value greater than the value found in literature [4] for the need of using a basket lift to access the roofs of multi-storey buildings;

- the replacement of $1 \%$ of the PV panels every year [58], and of all inverters every five years [59];

- the insurance costs, varying from $178.00 €$ to $297.00 €$ for PV systems with peak-power of $3 \mathrm{kWp}$ and $15 \mathrm{kWp}$, respectively.

- the yearly increasing in the price of electricity derived by the trend line calculated with the data issued by the AEEG (Autorità per l'energia elettrica e il gas) [60] and shown in Table 9.

- a net mean selling price of $0.102 € / \mathrm{kWh}$ was used for the gain in selling electricity, which was calculated on the basis of the exported PV energy [61].

- the net gain in selling the exported PV electricity was evaluated charging an income tax of $30.22 \%$, which was estimated on the basis of the average income of the inhabitants of Palermo [62].

- the electricity bills were calculated considering the difference between the bills corresponding to the electricity demand and those referred to the difference between the electricity demand and the energy consumed while the PV systems are producing electricity. The electricity tariffs issued by the AEEG - Italian Authority for electricity and gas for domestic consumers with an electricity capacity of $3 \mathrm{~kW}$ were used [63].

- the effect of inflation with a consumer price index of Table 9 [64], used to time-discount the costs during the time.

In order to evaluate the actual values of the gross energy cover factor $C_{\mathrm{PV}}$ of the district only the PV electricity generated by PV systems, whose installation had resulted economically convenient, was considered useful to cover the demand of the district. Fig. 9 shows the yearly gross energy cover factors filtered to take account of the economic assessment; the calculations are referred to January 2011.

The comparison with Fig. 3 shows the significant reduction of the gross energy cover factors due to the assessment of the economic convenience of PV installations; the gross energy cover factor of the district lowers from $35.8 \%$ to $24.5 \%$, with a percentage decrement of $31.6 \%$. The reduction of the gross energy cover factors is even severer if the shadowing is considered. The effect of 
Filtered gross energy cover factor $C_{P V}$ for the whole district

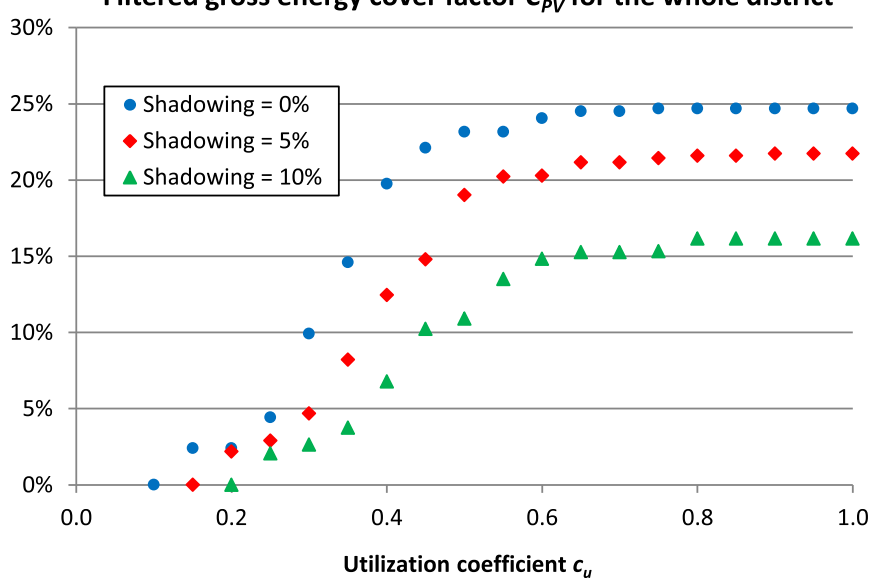

Fig. 10. Yearly gross energy cover factors for the whole district, filtered by the economic assessment, at various values of the shading coefficient versus utilization coefficient $c_{\mathrm{u}}$.

shadowing was considered by means of a shading coefficient varying from zero (no shading) to $100 \%$ (no solar energy). Although the shading coefficient produces a reduction of the generated PV electricity that is directly proportional to its value, the effect on the gross cover energy factor is quite not proportional. With a reduction of $5 \%$ in the electricity generated by the PV systems, the gross energy cover factor of the district lowers to $21.5 \%$, which is a reduction of $12.2 \%$. The reduction is even greater with higher values of the shading coefficient; a reduction of $10 \%$ of the electrical generation due to the shadowing causes a decrement of $38.8 \%$ in the gross energy cover factor of the district.

The filtered gross energy cover factor is also affected by the mismatch. Actually, because $c_{\mathrm{u}}$ impacts on the amount of imported energy that is necessary to buy from the national grid, some PV systems may result economically ineffective. Fig. 10 shows the effect of utilization coefficient $c_{u}$ on the filtered gross energy cover factor of the district for different values of the shading coefficient.

As it was expected, all PV systems become economically ineffective when a very small amount of the electricity demand is covered by the PV generation. Adversely, the mismatch has a very small effect on the gross energy cover factor when more than $60 \%$ of

Load match index $\gamma_{D}$ for the whole district

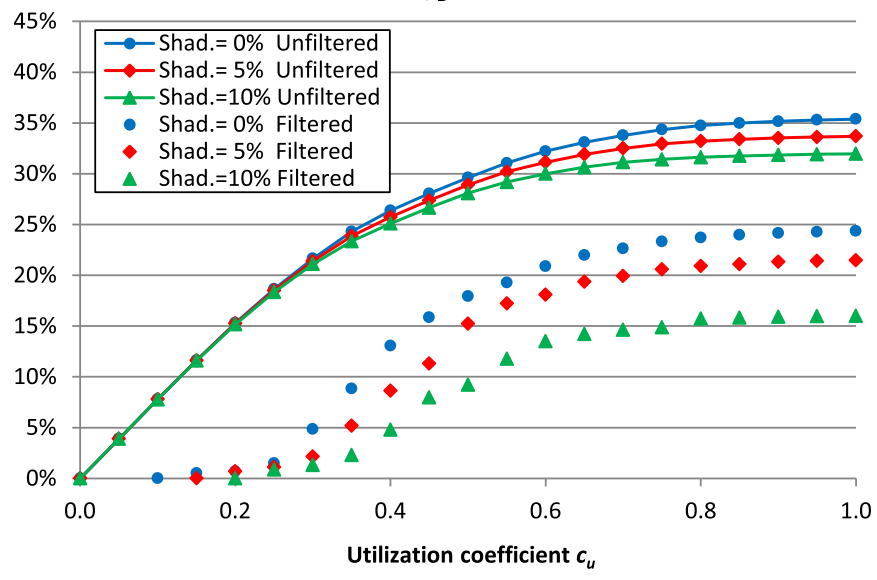

Fig. 11. Yearly load match index for the whole district (with economically filtered and unfiltered data) at various values of the shading coefficient versus utilization coefficient $c_{\mathrm{u}}$.
Filtered load match index (LMI) for the whole district

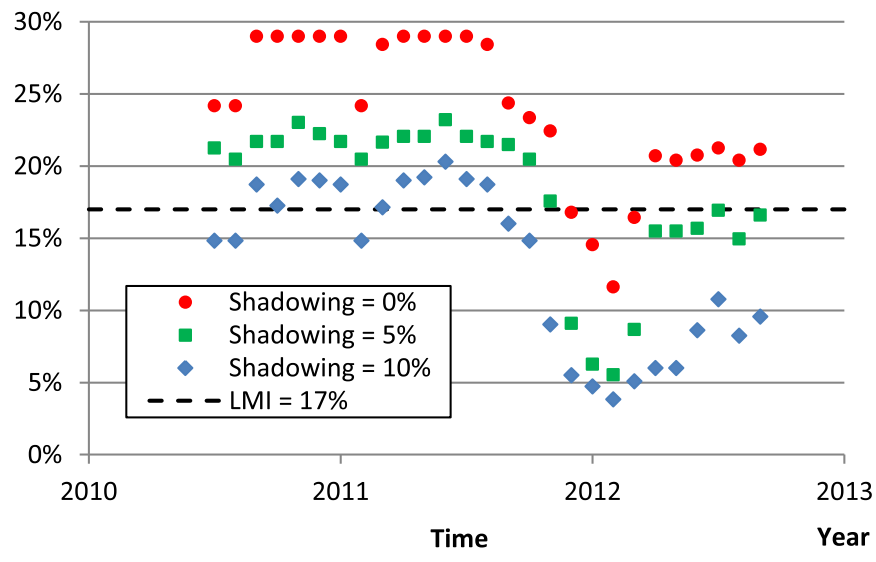

Fig. 12. Time variation of the yearly load match index for the whole district at various values of the shading coefficient with a unit value of $c_{\mathrm{u}}$.

the electricity demand is covered by the PV generation (a reduction of $0.73 \%$ and $1.96 \%$ with shadowing coefficients of $0 \%$ and $10 \%$, respectively). For values of $c_{\mathrm{u}}$ less than $60 \%$ an abrupt abatement of $C_{\mathrm{PV}}$ is observed. In Fig. 11 the variation of load match index $\gamma_{\mathrm{D}}$ is shown.

Load match index is directly affected by the mismatch. If the unfiltered values of PV generation are considered, $\gamma_{D}$ gradually decreases with utilization coefficient $c_{\mathrm{u}}$ and its reduction is also linearly proportional to the shading coefficient. Load match index is $35.4 \%$ if no shadowing effect is considered; it lowers to $32.0 \%$ with a shading coefficient of $10 \%$. The linear proportionality with the shading coefficient is not kept when the filtered values of PV generation are considered; load match index is $24.4 \%$ if no shadowing effect is considered; it lowers to $16.0 \%$ with a shading coefficient of $10 \%$. Because mismatch values varying from $40 \%$ to $60 \%$ are not uncommon occurrences, smart habits in using household appliances should be adopted and modern building automation systems may be installed to better harness the PV electricity.

On the basis of the above graphics it may be inferred that, if adequate values of the shading and utilization coefficients are assumed, the PV generation should permit to achieve the target value of $17 \%$ established by the Directive 2009/28/EC for Italy [65]. These conclusions are doomed to change during the time because the discount rate, which is the parameter mainly affecting the

Filtered load match index (LMI) for the whole district

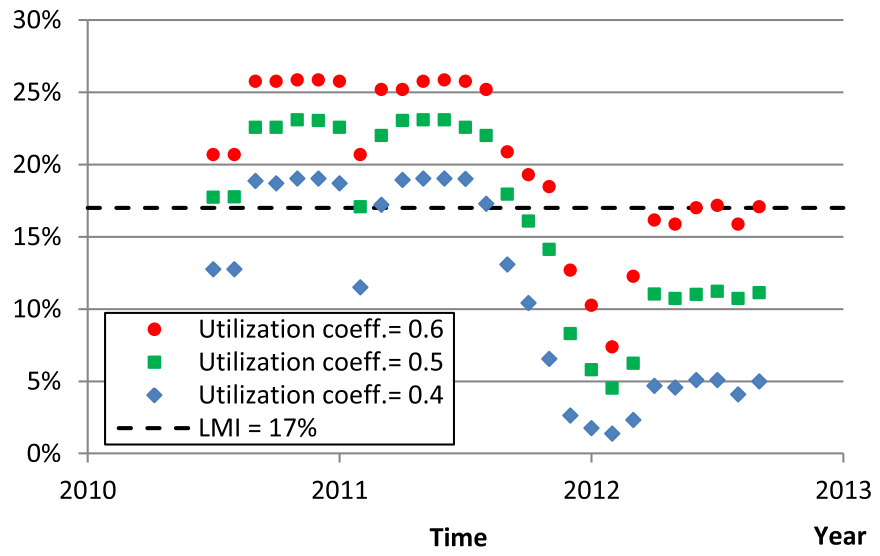

Fig. 13. Time variation of the yearly load match index for the whole district at various values of $c_{\mathrm{u}}$ with a null value of the shading coefficient. 
economic assessment, even though had begun to increase since October 2010, was still small in January 2011. The surge of the discount rate during the second part of 2011 is dramatically shown in Fig. 12 where the trend of the filtered load match index, calculated assuming the complete matching between generated and consumed electricity $\left(c_{\mathrm{u}}=1\right)$, is depicted.

The combined effects of the FIT de-escalation and the rise of the discount rate not significantly perceived till July 2011. The situation got worse in August and was definitely unsatisfactory at the end of 2011. The load match index, calculated assuming a null value of the shading coefficient, lowers from almost $30 \%$ to less than $15 \%$. A reduction of $70 \%$ is observed with a shading coefficient equal to $10 \%$. A similar behaviour can be noticed observing Fig. 13 in which the effect of the mismatch is highlighted.

The load match index, which is greater than $17 \%$ even though a small value of the utilization coefficient $\left(c_{\mathrm{u}}=0.4\right)$ is considered, almost vanishes in January 2012. Because it is not expected that the incentives will increase, only a significant reduction of the discount rate may trace back the load match index to a value greater than $17 \%$.

\section{Conclusion}

This paper provides a procedure for estimating the potential of PV systems in urban contexts in accordance with the variation of the main economic parameters and financial incentives. The procedure, which permits to associate the energy aspects connected to the specific architectural features with the economic assessment, was used to display the actual percentage of electrical coverage for a district of Palermo (South of Italy). The energy assessment focused on the calculation of the roof surfaces suitable for PV systems in accordance with the shape, orientation and number of floors of the building of the district. Such task was performed by means of the images provided by Google Earth ${ }^{\mathrm{TM}}$ software. The economic analysis was carried out month by month over the period from June 2010 to August 2012.

The results of the analysis showed that the risks for the investors crucially depend on the variation of the discount rate. Till the first semester of 2011 the reduction of the feed-in tariffs was compensated by the decrease in the costs of PV devices. Such situation, due to a value of the discount rate varying between $3.8 \%$ and $4.7 \%$, has guaranteed a high level of energy coverage. Starting from July 2011 the match load index has shown a downward trend that reached the lowest level in January 2012, when the discount rate overtook $5.5 \%$. The surge of the discount rate, which was influenced by the financial crisis, reduced the match load index of the district to values much lower than $17 \%$, which is the Italian target imposed by the Directive 2009/28/EC.

\section{Nomenclature}

$C_{\mathrm{PV}} \quad$ gross energy cover factor of the district [\%]

$C_{\mathrm{t}} \quad$ cash flow at the generic $t$-th year $[€]$

$c_{\mathrm{u}} \quad$ utilization coefficient $c_{\mathrm{u}}$

$C_{0} \quad$ initial investment cost $[€]$

$D_{\text {Day } j} \quad$ day electricity demand of the generic $j$-th PV system [kWh]

$D_{j}^{*} \quad$ electricity demand of the generic $j$-th PV system [kWh]

$D_{j} \quad$ electricity demand of the generic $j$-th PV system during the generic $i$-th time interval [kWh]

$D_{\text {Match } j}$ matched energy demand of the generic $j$-th PV system [kWh]

$D_{\mathrm{Mism}, j} \quad$ mismatched energy demand of the generic $j$-th PV system [kWh]

$D_{\text {Night } j} \quad$ night electricity demand of the generic $j$-th PV system [kWh]
$D_{\text {Total }} \quad$ yearly electricity demand of the district [ $\mathrm{kWh}$ ]

$E_{\exp j} \quad$ electricity exported by the generic $j$-th PV system during the generic $i$-th time interval [kWh]

$E_{\text {imp } j} \quad$ electricity imported by the generic $j$-th PV system during the generic $i$-th time interval $[\mathrm{kWh}]$

$E_{\mathrm{PV}, j}^{*} \quad$ yearly electricity produced by the generic $j$-th PV system [kWh]

$E_{\mathrm{PV}, j} \quad$ electricity generated by the generic $j$-th PV system during the generic $i$-th time interval [ $\mathrm{kWh}]$

$E_{\mathrm{PVload}, j}^{*}$ electricity supplied to the load by the generic $j$-th PV system [kWh]

$E_{\text {PVload } j}$ electricity supplied to the load by the generic $j$-th PV system during the generic $i$-th time interval [kWh]

$E_{\text {PVTotal }}$ yearly electricity produced by all PV systems [kWh]

$k$ discount rate [\%]

IRR internal rate of return [\%]

$N \quad$ number of samples in the evaluation period

$N_{P V} \quad$ number of PV systems

NPV net present value $[€]$

$N_{t} \quad$ lifetime of the investment [years]

$t \quad$ generic $t$-th year

$\gamma_{\mathrm{D}} \quad$ load match index of the district [\%]

$\gamma_{\mathrm{D}, j} \quad$ load match index of the generic $j$-th PV system [\%]

$\gamma_{\mathrm{D}, \mathrm{u}} \quad$ load match index of the district referred to the utilization coefficient [\%]

\section{References}

[1] Real Decreto $1565 / 2010$, de 19 de noviembre, por el que se regulan y modifican determinados aspectos relativos a la actividad de producción de energía eléctrica en régimen especial. Boletin Oficial del Estado 283.

[2] Real Decreto $1 / 2012$, de 27 de enero, por el que se procede a la suspensión de los procedimientos de preasignación de retribución y a la supresión de los incentivos económicos para nuevas instalaciones de producción de energía eléctrica a partir de cogeneración, fuentes de energía renovables y residuos. Boletin Oficial del Estado 24

[3] Renewable Energy Sources Act of 25 October 2008 (Federal Law Gazette I p. 2074) as last amended by the Act of 11 August 2010 (Federal Law Gazette I, p. 1170).

[4] Celik AN. Present status of photovoltaic energy in Turkey and life cycle techno-economic analysis of a grid-connected photovoltaic-house. Renew Sustain Energy Rev 2006;10:370-87.

[5] Stritih U, Zupan G, Butala V. Review of green electricity production in Slovenia. Renew Sustain Energy Rev 2007;11:2201-8.

[6] Zahedi A. Development of an economical model to determine an appropriate feed-in tariff for grid-connected solar PV electricity in all states of Australia. Renew Sustain Energy Rev 2008;13:871-8.

[7] Poullikkas A. Parametric cost-benefit analysis for the installation of photovoltaic parks in the island of Cyprus. Energy Policy 2009;37:3673-80.

[8] Danchev S, Maniatis G, Tsakanifas A. Returns on investment in electricity producing photovoltaic systems under de-escalating feed-in-tariffs: the case of Greece. Renew Sustain Energy Rev 2009;14:500-5.

[9] Papadopoulos AM, Karteris MM. An assessment of the Greek incentives scheme for photovoltaics. Energy Policy 2009;37:1945-52.

[10] Campoccia A, Dusonchet L, Telaretti E, Zizzo G. Comparative analysis of different supporting measures for the production of electrical energy by solar PV and wind systems: four representative European cases. Sol Energy 2009;83:287-97.

[11] Lüthi S. Effective deployment of photovoltaics in the Mediterranean countries: balancing policy risk and return. Sol Energy 2010;84:1059-71.

[12] Rigter J, Vidican G. Cost and optimal feed-in-tariff for small scale photovoltaic systems in China. Energy Policy 2010;38:6989-7000.

[13] Dusonchet L, Telaretti E. Economic analysis of different supporting policies for the production of electrical energy by solar photovoltaics in western European Union countries. Energy Policy 2010;38:3297-308.

[14] Dusonchet L, Telaretti E. Economic analysis of different supporting policies for the production of electrical energy by solar photovoltaics in eastern European Union countries. Energy Policy 2010;38:4011-20.

[15] Dinçer F. The analysis on photovoltaic electricity generation status, potential and policies of the leading countries in solar energy. Renew Sustain Energy Rev 2011;15:713-20.

[16] Sivaraman D, Horne RE. Regulatory potential for increasing small scale grid connected photovoltaic (PV) deployment in Australia. Energy Policy 2011;39: $586-95$.

[17] Al Badi AH, Albadi MH, al-Lawati AM, Malik AS. Economic perspective of PV electricity in Oman. Energy 2011;36:226-32. 
[18] Van der Zwaan B, Rabl A. The learning potential of photovoltaics: implications for energy policy. Energy Policy 2004;32:1545-54.

[19] Celik AN, Muneer T, Clarke P. A review of installed solar photovoltaic an thermal collector capacities in relation to solar potential for the EU-15. Renew Energy 2009;34:849-56.

[20] Kelleher J, Ringwood JV. A computational tool for evaluating the economics of solar and wind microgeneration of electricity. Energy 2009:34:401-9.

[21] Hongbo R, Weijun G, Yingjun R. Economic optimization and sensitivity analysis of photovoltaic system in residential buildings. Renew Energy 2009;34:883-9.

[22] Al-Salaymeh A, Al-Hamamre Z, Sharaf F, Abdelkader MR. Technical and economical assessment of the utilization of photovoltaic systems in residential buildings: the case of Jordan. Energy Convers Manag 2010;51:1719-26.

[23] Li Z, Boyle F, Reynolds A. Domestic application of solar PV systems in Ireland: The reality of their economic viability. Energy 2011;36:5865-76.

[24] Myers KS, Klein SA, Reindl DT. Assessment of high penetration of solar photovoltaics in Wisconsis. Energy Policy 2010:38:7338-45.

[25] Muñoz FJ, Echbarthi I, Nofuentes G, Fuentes M, Aguilera J. Estimation of the potential array output charge in the performance analysis of stand-alone photovoltaic systems without MPPT (case study: Mediterranean climate). Sol Energy 2009;83:1985-97.

[26] Mavromatakis F, Makrides G, Georghiou G, Pothrakis A, Franghiadakis Y Drakakis E, et al. Modeling the photovoltaic potential of a site. Renew Energy 2010;35:1387-90

[27] Rüther R, Braun P. Energetic contribution potential of building-integrated photovoltaics on airports in warm climates. Sol Energy 2009:83:1923-31.

[28] Rihab J, Lotfi K. Sizing, techno-economic and generation management analysis of a stand alone photovoltaic power unit including storage devices. Energy 2012;40:196-209.

[29] Castro M, Delgado A, Argul F, Colmenar A, Yves F, Peire J. Grid-connected PV buildings: analysis of future scenarios with an example of Southern Spain. Sol Energy 2005;79:86-95.

[30] Šúri M, Huld TA, Dunlop ED, Ossenbrink HA. Potential of solar electricity generation in the European Union member states and candidate countries. So Energy 2007;81:1295-305.

[31] Hofierka J, Kaňuk J. Assessment of photovoltaic potential in urban areas using open-source solar radiation tools. Renew Energy 2009;34:2206-14.

[32] Defaix PR, van Sark WGJHM, Worrell E, de Visser E. Technical potential for photovoltaics on buildings in the EU-27. Sol Energy 2011;86:2644-53.

[33] Ordóñez J, Jadraque E, Alegre J, Martínez G. Analysis of the photovoltaic solar energy capacity of residential rooftops in Andalusia (Spain). Renew Sustain Energy Rev 2010;14:2122-30.

[34] Vardimon R. Assessment of the potential for distributed photovoltaic electricity production in Israel. Renew Energy 2011;36:591-4.

[35] Izquierdo S, Rodrigues M, Fueyo N. A method for estimating the geographical distribution of the available roof surface area for large-scale photovoltaic energy-potential evaluations. Sol Energy 2008;82:929-39.

[36] Sorensen B. GIS management of solar resource data. Sol Energy Mater Sol Cells 2001;67(1-4):503-9.

[37] Wiginton LK, Nguyen HT, Pearce JM. Quantifying rooftop solar photovoltaic potential for regional renewable energy policy. Comput Environ Urban Syst 2010;34:345-57.

[38] Nguyen HT, Pearce JM. Estimating potential photovoltaic yield with r.sun and the open source geographical resources analysis support system. Sol Energy 2010;84:831-43.

[39] Viana TS, Rüther R, Martins FR, Pereira EB. Assessing the potential of concentrating solar photovoltaic generation in Brazil with satellite-derived direct normal irradiation. Sol Energy 2011;85:486-95.

[40] Cellura M, Di Gangi A, Longo S, Orioli A. Photovoltaic electricity scenario analysis in urban context: an Italian case study. Renew Sustain Energy Rev 2012;16:2041-52.

[41] PVsyst. Software for photovoltaic systems. D7, route de Drize CH-1227 Carouge Switzerland: University of Geneva ISE - Group Energy, FOREL Battelle, bât: 2010.

[42] Dati Statistici sull'energia elettrica in Italia, Terna S.p.A., www.terna.it/default/ Home/SISTEMA_ELETTRICO/statistiche/dati_statistici.aspx.
[43] Dati statistici ISTAT: Popolazione residente - Censimento 2001-Superficie delle abitazioni occupate da persone residenti, ISTAT, Italian National Institute of Statistics, dawinci.istat.it/MD/dawinciMD.jsp.

[44] Widén J, Wäckelgard E, Lund PD. Options for improving the load matching capability of distributed photovoltaics: methodology and application to highlatitude data. Sol Energy 2009;83:1953-66.

[45] Voss K, Sartori I, Napolitano A, Geier S, Gonzalves H, Hall M, et al. Load matching and grid interaction of net zero energy buildings. In: EUROSUN 2010, International conference on solar heating, cooling and buildings, Graz, Austria, 29 September - 1 October 2010.

[46] Verbruggen B, De Coninck R, Baetens R, Saelens D, Helsen L, Driesen J. Grid impact indicators for active building simulation. In: IEEE PES conference on innovative smart grid technologies conference, Anaheim, California, US, 1719 January 2011.

[47] Project EURECO. Demand-side management, end-use metring campaign in 400 households of the European community, assessment of the potentia electricity savings; 2002.

[48] eERG, end-use Efficiency Research Group, Politecnico di Milano. MICENE Misure dei consumi di energia elettrica in 110 abitazioni italiane, curve di carico dei principali elettrodomestici e egli apparecchi di illuminazione; 2004

[49] IES, Institute for Environment and sustainability - JRC, Joint Research Centre - European Commission. Electricity consumption and efficiency trends in the enlarged European Union. Status Report; 2006.

[50] IEA, International Energy Agency. Final report of annex 42 - energy conservation in buildings and community system programme; 2008.

[51] Decreto Ministeriale 19 febbraio 2007-Criteri e modalita' per incentivare la produzione di energia elettrica mediante conversione fotovoltaica della fonte solare. In: attuazione dell'articolo 7 del decreto legislativo 29 dicembre 2003, p. 387.

[52] Decreto Ministeriale 6 agosto 2010-Incentivazione della produzione di energia elettrica mediante conversione fotovoltaica della fonte solare.

[53] Decreto Ministeriale 5 maggio 2011 - Criteri per incentivare la produzione di energia elettrica da impianti solari fotovoltaici e lo sviluppo di tecnologie innovative per la conversione fotovoltaica.

[54] www.solarbuzz.com/facts-and-figures/retail-price-environment: B_Retail Pricing_110509.xlsx, 2012.

[55] www.indexmundi.com/commodities/?commodity=copper\&;months=60, 2012.

[56] Banca d'Italia, (2010, 2011, 2012). http://www.bancaditalia.it/banca_centrale/ operazioni/titoli/tassi/rendi/2010/rendistato_2010.pdf. http://www. bancaditalia.it/banca_centrale/operazioni/titoli/tassi/rendi/2011/rendistato 2011.pdf. http://www.bancaditalia.it/banca_centrale/operazioni/titoli/tassi/ rendi/2012/rendistato-2012.pdf.

[57] Kyocera. http://www.kyocerasolar.com/assets/001/5150.pdf.

[58] SMA Solar Technology. http://www.sma-uk.com/en_UK/products/solarinverters/sunny-boy/sunny-boy-3000tl-3600tl-4000tl-5000tl-with-reactivepower-control.html.

[59] Jordan DC, Smith RM, Osterwald CR, Gelak E, Kurtz SR. Outdoor PV degradation comparison. In: 35th IEEE photovoltaic specialists conference (PVSC '10), Honolulu, Hawaii, June 20-25, 2010.

[60] AEEG - Autorità per l'energia elettrica e il gas. http://www.autorita.energia.it/ it/dati/eep45.htm.

[61] GSE Gestore Servizi Energetici. http://www.gse.it/GSE_UltimiDocumenti Ritiro\%20e\%20scambio/Ritiro\%20dedicato/Guide\%20Manuali\%20Modulistica/ 03\%20In\%20pagina/Dati\%20e\%20Pubblicazioni\%20informative/02\%20Prezzi/ Prezzi\%20minimi\%20garantiti/2011/Prezzi\%20minimi\%20garantiti\%202011\% 20(24-01-11).pdf.

[62] Comuni Italiani. http://www.comuni-italiani.it/19/statistiche/redditip2010. html.

[63] AEEG-Autorità per l'energia elettrica e il gas. http://www.autorita.energia.it/ it/dati/condec.htm.

[64] ISTAT - Italian national Institute of statistics, (2012). www.istat.it/it/archivio/ 30440.

[65] Directive 2009/28/EC OF THE EUROPEAN PARLIAMENT AND OF THE COUNCIL of 23 April 2009 on the promotion of the use of energy from renewable sources and amending and subsequently repealing Directives 2001/77/EC and 2003/30/EC. 